\title{
Poisoning Due to Stored Medications at Home in Al-Qassim Region, Saudi Arabia
}

\author{
Afaf Badr Alenazi ${ }^{1}$, Mansour Saleh Alsharidah ${ }^{2}$, Amal Hassan Al-Najjar ${ }^{3, *}$, \\ Suliman Abdulaziz Alghazy ${ }^{4}$, Abdul-Aziz Abdullah Alqadi ${ }^{5}$, Amir Marzouk ${ }^{6}$ \\ ${ }^{1}$ College of Pharmacy, Qassim University, \\ ${ }^{2}$ Assistant Professor. Dean College of Pharmacy, Qassim University, \\ ${ }^{3}$ Drug Information Supervisor, SFHP-Riyadh, \\ ${ }^{4}$ College of Pharmacy, Qassim University, \\ ${ }^{5}$ Acute Clinical Care Supervisor, SFHP-Riyadh, \\ ${ }^{6}$ The research center College of Medicine, King Saud University KSA.
}

\begin{abstract}
Objective: Storing medications at home is a global practice. By storing medications in an appropriate and safe environment, we can prevent accidental poisoning. Information is scarce regarding the storage of different types of medications at homes in Al-Qassim region, Kingdom of Saudi Arabia. Therefore, in this study, we aimed to explore the cases of poisoning due to stored medications at home in Al-Qassim region. Methodology: This is a descriptive, cross-sectional survey conducted through the random distribution of a pre-validated structured questionnaire among the public and private sector employees and people from all walks of life above the age of 18 years in Al-Qassim region. The survey was designed electronically through the Survey Monkey system and was distributed through social media. Results: A total of 708 subjects responded to the survey. Most of the responders $(485(68.10 \%))$ were females. About half of the responders were in the age group of $18-29$ years $(393(58.31 \%)$ ) with females being significantly dominant than males $(p<0.05)$. Majority of the responders stored their medications separated from households' chemicals (524 (77.06\%)). Most of the responders did not store multiple medications in the same container without any significant difference related to gender or educational level $(p>0.05)$. The total number of poisonous cases were 41 (5.79\%) without any significant difference related to gender or educational level $(p>0.05)$. Poisoning due to medications were mostly caused due to the medications stored in refrigerator $(15(40.54 \%))$ and bedroom $(10(27.03 \%))$. Most of the stored medications were disposed into the trash after their expiry dates (463 (65.4\%)) while 189 items remained at home (26.69\%). A total of 33 different types of stored medications caused poisoning in 44 cases. Paracetamol caused 6 cases of poisoning (18.18\%), followed by ibuprofen 3 (9.09\%) and multivitamins 3 (9.09\%). Conclusion: The results of this study revealed an alarming setting of poisoning cases due to stored medications in Al-Qassim region. Awareness campaigns and more educational sessions should be conducted through social media. By doing so, people can be educated regarding the proper storage of medications to prevent poisoning. Thus, public awareness programs stressing on the safe storage and identification of the right ways to dispose of medication are highly recommended.
\end{abstract}

Key words: Poisoning, Al-Qassim, Medication storage, Home, Saudi Arabia.
Received: 12-10-2018;

Accepted: 18-12-2018

*Correspondence to:

Dr. Amal Hassan Al-Najjar

Drug Information Supervisor, Security Forces Hospital,

Riyadh, SAUDI ARABIA.

Phone no: +966504130480

Email: aalnajjar66@gmail.com

DOI: 10.5530/ijpcs.2019.8.12

Copyright: (c) the author(s),publisher and licensee International Journal of Pharmacology and Clinical Sciences. This is an open-access article distributed under the terms of the Creative Commons Attribution Non-Commercial License, which permits unrestricted non-commercial use, distribution, and reproduction in any medium, provided the original work is properly cited.

This is an open access article distributed under the terms of the Creative Commons AttributionNonCommercial-ShareAlike 4.0 License

Access this article online

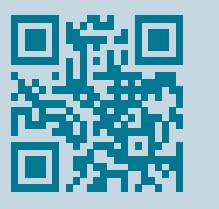

www.ijpcs.net 


\section{INTRODUCTION}

Every year new pharmaceutical products are being produced in huge quantities. Use of these products varies (either for diagnosis, disease prevention or for treatment). The increase in medication use has led to improper storage of medications at home, which leads to undesirable and unintentional adverse effects, for example, accidental overdose, drug abuse and improper self-medication. ${ }^{[1,2]}$ Most of the patients who store medications at home do not know how to read expiry date or how to store them in the right place or how to dispose them off properly and safely. ${ }^{[2]}$

The environmental consequences of the unused medications have made this issue a center of attention throughout the world. The stored medicines at home could lead to a lot of drug-related risks; one of which is the risk of accidental poisoning through ingestion of un-prescribed drugs, as well as, the risk of adverse drug reactions, through taking medication of other patients by mistake and even wastage of resources. There are even risks of accidental child poisoning and suicide cases, which has enhanced the gravity of the need for a proper disposal mechanism of medicines. Decreasing the percentage of leftover medications by addressing the issues that lead to the cause of this crisis is even more important than solving the disposal issue ${ }^{[3]}$ Bedrooms are usually the most common places for storage of medications; therefore, it can be readily understood that the medications are easily accessible to children which increases the risk of poisoning. ${ }^{[4]}$ There are many agents that cause poisoning including medications stored at homes, cleaning agents, cosmetics and household products. In many countries, medications are the mean cause of poisoning which is expected as they are easily available in every house. ${ }^{[5]}$ Preventing poisoning due to medications is a big challenge for both prescription and nonprescription medications especially in case of children, who have easy access to medicines. As per the data of US emergency departments, about two-thirds of the cases of poisoning in children were due to easy reach to the storage place. ${ }^{[6]}$ About 56,000 children visited the US emergency departments during the year of 2014 due to medications poisoning. ${ }^{[7]}$ Another study found that 831,295 visits to the emergency departments were for the same reason. ${ }^{[8]}$ Therefore, we conducted this study to explore the incidence of poisoning cases due to the storage of medications at home in Al-Qassim region, Saudi Arabia.

\section{METHODS}

This is a 1-month cross-sectional survey conducted through the random distribution of a pre-validated structured questionnaire in Al-Qassim region in 2017 to students, public and private sector employees and to people from all walks of life above the age of 18 years. The questionnaire was designed in English and the Arabic version was validated by the research team. The survey consisted two sections: the first section collected sociodemographic characteristics of the respondents. The second section collected information regarding any previous case(s) of poisoning and the location of the medication when the event occurred, the routine storage place of medicines at home and if the area is reachable by a child and about storage of multiple medications in the same container. The survey was designed electronically through a Survey Monkey system and was distributed through social media. In addition, 100 copies of the questionnaire were printed and then spread across all the areas of Al-Qassim region. The data were analyzed by using Survey Monkey system and SPSS version 22 .

\section{RESULTS}

A total of 708 subjects responded to this survey. Most of the responders were females (485 (68.10\%)). About half of the responders were in the age group of 18-29 years $(393(58.31 \%))$ with a significantly dominant female population than that of males $(p<0.05)$, whereas $30 \%$ (206) of the responders were in the age group of 30-39 years without any differences in the gender. Concerning the educational status, 592 (83.62\%) of the responders completed their higher education with a significantly dominant female population $(p<0.05)$. Most of the families comprised 5-7 members (299 $(42.23 \%)$ ) followed by families comprising more than 8-10 members $(183(26 \%))$ and families comprising 2-4 members (163 (23\%)), without any significant differences in the educational status. A total of 493 (69.63\%) responders had at least one elderly person in their home regardless of any significant differences in age or educational status $(p>0.05)$. However, 322 $(45.48 \%)$ responders had at least one family member who was working in the healthcare sector with females being significantly more than that of males and without any significant differences in educational status (Table 1). The most frequently recorded indication for stored medications was for "others" (355 (50.14\%)) and 314 indications were recorded for "chronic disease" $(44.35 \%)$ without any significant differences related to 


\begin{tabular}{|c|c|c|}
\hline & Response Count & $\begin{array}{l}\text { Response } \\
\text { Percent }\end{array}$ \\
\hline \multicolumn{3}{|l|}{ Sex } \\
\hline Female & 485 & $68.50 \%$ \\
\hline Male & 223 & $31.50 \%$ \\
\hline Answered questions & 708 & \\
\hline Skipped questions & 0 & \\
\hline \multicolumn{3}{|l|}{ Age } \\
\hline $18-29$ & 412 & $58.19 \%$ \\
\hline 30-39 & 216 & $30.51 \%$ \\
\hline 40-49 & 60 & $8.47 \%$ \\
\hline $50-59$ & 15 & $2.12 \%$ \\
\hline $60+$ & 5 & $0.71 \%$ \\
\hline Answered questions & 708 & \\
\hline Skipped questions & 0 & \\
\hline \multicolumn{3}{|l|}{ Educational status } \\
\hline Illiterate & 0 & $0.00 \%$ \\
\hline Primary/intermediate & 8 & $1.13 \%$ \\
\hline Secondary & 108 & $15.25 \%$ \\
\hline University / more & 592 & $83.62 \%$ \\
\hline Answered questions & 708 & \\
\hline Skipped question & 0 & \\
\hline \multicolumn{3}{|c|}{ How many family members in your house? } \\
\hline $2-4$ & 163 & $23.02 \%$ \\
\hline $5-7$ & 299 & $42.23 \%$ \\
\hline 8-10 & 183 & $25.85 \%$ \\
\hline More than 10 & 63 & $8.90 \%$ \\
\hline Answered questions & 708 & $23.02 \%$ \\
\hline Skipped questions & 0 & \\
\hline \multicolumn{3}{|c|}{ Do you have any elderly in your family? } \\
\hline Yes & 493 & $69.63 \%$ \\
\hline No & 215 & $30.37 \%$ \\
\hline Answered questions & 708 & \\
\hline Skipped questions & 0 & \\
\hline \multicolumn{3}{|c|}{ Is there any member in your family working in Health sector? } \\
\hline Yes & 322 & $45.48 \%$ \\
\hline No & 386 & $54.52 \%$ \\
\hline Answered questions & 708 & \\
\hline Skipped questions & 0 & \\
\hline
\end{tabular}

gender or educational status ( $p>0.05)$. It is noteworthy that females most frequently used medications for "other" diseases, whereas males most frequently used medications for acute illnesses. Most of the responders used the stored medications for their current use as was prescribed (436 (61.58\%)) without any significant differences related to gender or educational status $(p>0.05)$. It is noteworthy that males were intending to use the stored medications for future use, whereas female used medications for "other" needs $(p<0.05)$.
Most of the responders stored the medications away from the reach of children $(557(78.67 \%))$ with significant differences for female population than that of males $(p<0.05)$. It is noteworthy that secondary school responders tended to store medicines that can be easily reached by children regardless of gender or educational status $(p<0.05)$ (Tables 2 and 3). Most of the responders stored medications separated from household chemicals (524 (77.06\%)) with females dominating the category than that of males $(p<0.05)$ and without any significant differences with regard to educational status $(p>0.05)$. An increasing number of medications were stored separately from household chemicals $(p<0.05)$ (Tables 3 and 4$)$. Most of the responders did not store multiple medications in the same container without any significant differences related to gender or educational status $(p>0.05)$ except for that secondary school responders stored more medications than university degree holders. But it was noticed that with increasing the number of different stored medications, it will be difficult to keep them in the same container $(p<0.05)$ (Tables 2 and 5). A total number of 41 (5.79\%) poisonous cases were reported without any significant differences related to gender or educational status $(p>0.05)$. Most of the poisoning cases were due to the medications that were stored in the refrigerator $(15(40.54 \%))$ and in the bedroom $(10(27.03 \%))$ without any significant difference in relation to gender or educational status $(p>0.05)$ (Tables 2 and 3). Most of the stored medications were disposed in the trash (463 (65.4\%)), whereas some medications were stored at home (189 (26.69\%)) without any significant differences in relation to gender or educational status $(p>0.05)$. Males tended to store medications than that of females. Disposed of medications in the trash was significantly high than that of storage $(p<0.05)$ (Tables 2 and 6$)$. A total number of 33 medications were responsible for 44 poisoning cases. Paracetamol, ibuprofen and multivitamins were responsible for $6(18.18 \%), 3(9.09 \%)$ and $3(9.09 \%)$ poisoning cases (Table 7 ).

\section{DISCUSSION}

Nowadays, there is an increasing number of poisoning cases due to the accidental ingestion or exposure to stored medications at home. Therefore, there is a real need to address this. The risks of storing excess medications at home extend from accidental poisoning to drug abuse and ease of access to patients with suicidal tendencies. A variety of stored medicines are directly linked to the most prevalent diseases and is more or 


\section{Table 2: Determents of poisoning from stored medications. \\ Response Count Response Percent}

Do you know the indication of all type of medications you have?

\begin{tabular}{l|c}
\hline Others & 355 \\
\hline Chronic disease & 314 \\
\hline Supplements & 178 \\
\hline Acute illness & 116 \\
\hline Answered question & 708 \\
\hline Skipped question & 0
\end{tabular}

Why do keep these medications?

For current use

For future use

For any other needs

Answered questions

Skipped questions

55
14
16
08
0

\begin{tabular}{|l|l|}
\hline $50.14 \%$ \\
\hline $44.35 \%$ \\
\hline $25.14 \%$ \\
\hline $16.38 \%$ \\
\hline
\end{tabular}

F more than $\mathrm{M} P<0.05$

M more than $\mathrm{F} P<0.05$

$P>0.05$ in the Educational status factor

Do you store your medicines in a place that your child can easily reach?

\begin{tabular}{l|l} 
Yes & \\
\hline No & \\
\hline Answered questions & \\
\hline Skipped questions & \\
\hline
\end{tabular}

\begin{tabular}{|c|c|}
\hline 151 & $21.33 \%$ \\
\hline 557 & $78.67 \%$ \\
\hline 708 & \\
\hline 0 & \\
\hline
\end{tabular}

$P<0.05$ in the gender factor

$P>0.05$ in the Educational status factor except at secondary level more to store medication that child can easily reach than university level

Do you store your family's medications separated from those of household chemicals?

\begin{tabular}{|c|c|c|c|}
\hline Yes & 524 & $77.06 \%$ & \multirow{4}{*}{$\begin{array}{l}P<0.05 \text { in the gender factor } \\
P>0.05 \text { in the Educational status factor }\end{array}$} \\
\hline No & 156 & $22.94 \%$ & \\
\hline Answered questions & 680 & & \\
\hline Skipped questions & 28 & & \\
\hline \multicolumn{4}{|c|}{ Is there any previous case of medication poisoning that happened at your home? } \\
\hline Yes & 41 & $5.79 \%$ & \multirow{3}{*}{$\begin{array}{l}P>0.05 \text { in the gender factor } \\
P>0.05 \text { in the Educational status factor }\end{array}$} \\
\hline Answered questions & 708 & & \\
\hline Skipped questions & 0 & & \\
\hline \multicolumn{4}{|c|}{ If yes; where was the medication when the poisoning happened? } \\
\hline Refrigerator & 15 & $40.54 \%$ & \multirow{6}{*}{$\begin{array}{l}P>0.05 \text { in the gender factor } \\
P>0.05 \text { in the Educational status factor }\end{array}$} \\
\hline Bedroom & 10 & $27.03 \%$ & \\
\hline Hand bag & 4 & $10.81 \%$ & \\
\hline Bathroom & 1 & $2.70 \%$ & \\
\hline Answered questions & 671 & & \\
\hline Skipped questions & 37 & & \\
\hline \multicolumn{4}{|c|}{ Do you store multiple medications in the same vial? } \\
\hline Yes & 89 & $13.09 \%$ & \multirow{5}{*}{$\begin{array}{l}P>0.05 \text { in the gender factor } \\
P>0.05 \text { in the Educational status factor except at secondary } \\
\text { level more mostly to store multiple medication than university } \\
\text { level }\end{array}$} \\
\hline Mostly & 89 & $13.09 \%$ & \\
\hline No & 502 & $73.82 \%$ & \\
\hline Answered questions & 680 & & \\
\hline Skipped questions & 28 & & \\
\hline \multicolumn{4}{|c|}{ How do you dispose unwanted drugs? } \\
\hline Trash & 463 & $65.40 \%$ & \\
\hline Given to other & 34 & $4.80 \%$ & \multirow[t]{4}{*}{$P>0.05$ in the Educational status factor } \\
\hline Return to the pharmacy & 22 & $3.11 \%$ & \\
\hline Answered questions & 708 & & \\
\hline Skipped questions & 0 & & \\
\hline
\end{tabular}




\begin{tabular}{|c|c|c|c|c|}
\hline \multicolumn{5}{|c|}{$\begin{array}{l}\text { Do you store your medicines in a place that your child } \\
\text { can easily reach? }\end{array}$} \\
\hline Gender & Yes & No & Total & $P$ value \\
\hline \multirow{3}{*}{ Male (A) } & $29.15 \%$ & $70.85 \%$ & $31.50 \%$ & \\
\hline & 65 & 158 & 223 & \\
\hline & B & B & & $P<0.05$ \\
\hline \multirow{3}{*}{ Female (B) } & $17.73 \%$ & $82.27 \%$ & $68.50 \%$ & \\
\hline & 86 & 399 & 485 & \\
\hline & A & A & & $P<0.05$ \\
\hline Total Respondents & 151 & 557 & 708 & \\
\hline \multicolumn{5}{|c|}{$\begin{array}{l}\text { Do you store your family's medications separated from } \\
\text { those of household chemicals? }\end{array}$} \\
\hline Gender & Yes & No & Total & $P$ value \\
\hline \multirow{3}{*}{ Male (A) } & $68.37 \%$ & $31.63 \%$ & $31.62 \%$ & \\
\hline & 147 & 68 & 215 & \\
\hline & B & B & & $P<0.05$ \\
\hline \multirow{3}{*}{ Female (B) } & $81.08 \%$ & $18.92 \%$ & $68.38 \%$ & \\
\hline & 377 & 88 & 465 & \\
\hline & A & A & & $P<0.05$ \\
\hline Total Respondents & 524 & 156 & 680 & \\
\hline
\end{tabular}

Table 4: Number of medications versus place of medication storage and household chemicals.

\begin{tabular}{|l|c|c|c|c|}
\hline $\begin{array}{l}\text { Number of } \\
\text { medications }\end{array}$ & Yes & No & Total & P value \\
\hline \multirow{3}{*}{ One Medications (A) } & $77.78 \%$ & $22.22 \%$ & $3.97 \%$ & \\
\cline { 2 - 5 } & 21 & 6 & 27 & \\
\hline \multirow{4}{*}{ Two Medications (B) } & $67.86 \%$ & $32.14 \%$ & $8.24 \%$ & \\
\cline { 2 - 5 } & 38 & 18 & 56 & \\
\cline { 2 - 5 } & $\mathrm{E}$ & $\mathrm{E}$ & & $P<0.05$ \\
\hline \multirow{3}{*}{ Three Medications (C) } & $70.41 \%$ & $29.59 \%$ & $14.41 \%$ & \\
\cline { 2 - 5 } & 69 & 29 & 98 & \\
\cline { 2 - 5 } & $\mathrm{E}$ & $\mathrm{E}$ & & $P<0.05$ \\
\hline \multirow{3}{*}{ Four Medications (D) } & $73.97 \%$ & $26.03 \%$ & $10.74 \%$ & \\
\cline { 2 - 5 } & 54 & 19 & 73 & \\
\hline \multirow{3}{*}{$\begin{array}{l}\text { Five or more } \\
\text { Medications (E) }\end{array}$} & $80.28 \%$ & $19.72 \%$ & $62.65 \%$ & \\
\cline { 2 - 5 } & 342 & 84 & 426 & \\
\cline { 2 - 5 } & $\mathrm{BC}$ & $\mathrm{BC}$ & & $P<0.05$ \\
\hline Total Respondents & 524 & 156 & 680 & \\
\hline
\end{tabular}

less similar to the different populations of the world. Paracetamol is considered to be relatively harmless and is usually stored for future emergency use. The results of this study have revealed that paracetamol is the most frequently stored medications in the studied population, followed by non-steroidal antiinflammatory drugs such as ibuprofen and diclofenac. This fraction was highest for analgesics than what was noticed in Qatar population, whereas nonsteroidal anti-inflammatory drugs were found to contribute less

\begin{tabular}{|c|c|c|c|c|c|}
\hline $\begin{array}{l}\text { Number of } \\
\text { medications }\end{array}$ & Yes & Mostly & No & Total & $\begin{array}{l}P \\
\text { value }\end{array}$ \\
\hline \multirow{2}{*}{$\begin{array}{l}\text { One Medications } \\
\text { (A) }\end{array}$} & $7.41 \%$ & $7.41 \%$ & $85.19 \%$ & $3.97 \%$ & \\
\hline & 2 & 2 & 23 & 27 & \\
\hline \multirow{3}{*}{$\begin{array}{l}\text { Two Medications } \\
\text { (B) }\end{array}$} & $3.57 \%$ & $14.29 \%$ & $82.14 \%$ & $8.24 \%$ & \\
\hline & 2 & 8 & 46 & 56 & \\
\hline & $\mathrm{DE}$ & & & & $P<0.05$ \\
\hline \multirow{2}{*}{$\begin{array}{l}\text { Three } \\
\text { Medications (C) }\end{array}$} & $13.27 \%$ & $18.37 \%$ & $68.37 \%$ & $14.41 \%$ & \\
\hline & 13 & 18 & 67 & 98 & \\
\hline \multirow{3}{*}{$\begin{array}{l}\text { Four Medications } \\
\text { (D) }\end{array}$} & $15.07 \%$ & $9.59 \%$ & $75.34 \%$ & $10.74 \%$ & \\
\hline & 11 & 7 & 55 & 73 & \\
\hline & $B$ & & & & $P<0.05$ \\
\hline \multirow{3}{*}{$\begin{array}{l}\text { Five or more } \\
\text { Medications (E) }\end{array}$} & $14.32 \%$ & $12.68 \%$ & $73.00 \%$ & $62.65 \%$ & \\
\hline & 61 & 54 & 311 & 426 & \\
\hline & B & & & & $P<0.05$ \\
\hline $\begin{array}{l}\text { Total } \\
\text { Respondents }\end{array}$ & 89 & 89 & 502 & 680 & \\
\hline
\end{tabular}

than that of the stored medicines in both Qatar and Mexico. ${ }^{[1,4]}$ Unintentional or accidental poisoning in children is a serious issue associated with the improper and surplus storage of medicines at home. About 92\% of the poisoning cases were found as unintentional in a study conducted on Palestine population. ${ }^{[5]}$ Similarly, 95\% of the poisoning cases in children were found to be due to prescription drugs in the US population. ${ }^{[8]}$ This raises the concern that more than prescription medications, over the counter drugs are more responsible for causing increased cases of poisoning. Vitamin and iron supplements were the second most type of the stored medicines in this study; they also contributed to accidental poisoning cases as they can be obtained as over the counter medicines. These supplements were also found as a result of storing the unused drugs in a Mexican population. ${ }^{[1]}$ In this study, the authors found that most of the responders stored their medications for the treatment of chronic disease. However, males mostly stored the medications for acute illnesses and for future usage when compared to females. In other words, males stored medications for future emergency purposes, whereas females stored the medications for chronic diseases. Most of the responders stored the medications away from the reach of children; this was found to be true for females because they feel more responsible toward children than males. Although two-thirds of the responders stored the medications away from the reach of children. Responders with low educational status were the least to store medications away from children because of they lack the knowledge of 


\begin{tabular}{|c|c|c|c|c|c|c|}
\hline $\begin{array}{l}\text { Number of } \\
\text { medications }\end{array}$ & Trash & $\begin{array}{l}\text { Return to the } \\
\text { pharmacy }\end{array}$ & $\begin{array}{l}\text { Given to } \\
\text { others }\end{array}$ & $\begin{array}{l}\text { Kept } \\
\text { them }\end{array}$ & Total & $P$ value \\
\hline \multirow{2}{*}{ One Medications (A) } & $70.37 \%$ & $0.00 \%$ & $3.70 \%$ & $25.93 \%$ & $3.81 \%$ & \\
\hline & 19 & 0 & 1 & 7 & 27 & \\
\hline \multirow{3}{*}{ Two Medications (B) } & $75.44 \%$ & $1.75 \%$ & $1.75 \%$ & $21.05 \%$ & $8.05 \%$ & \\
\hline & 43 & 1 & 1 & 12 & 57 & \\
\hline & E & & & & & $P<0.05$ \\
\hline \multirow{3}{*}{ Three Medications (C) } & $74.00 \%$ & $1.00 \%$ & $3.00 \%$ & $22.00 \%$ & $14.12 \%$ & \\
\hline & 74 & 1 & 3 & 22 & 100 & \\
\hline & E & & & & & $P<0.05$ \\
\hline \multirow{3}{*}{ Four Medications (D) } & $74.68 \%$ & $1.27 \%$ & $5.06 \%$ & $18.99 \%$ & $11.16 \%$ & \\
\hline & 59 & 1 & 4 & 15 & 79 & \\
\hline & $\mathrm{E}$ & & & $\mathrm{E}$ & & $P<0.05$ \\
\hline \multirow{3}{*}{ Five or more Medications (E) } & $60.22 \%$ & $4.27 \%$ & $5.62 \%$ & $29.89 \%$ & $62.85 \%$ & \\
\hline & 268 & 19 & 25 & 133 & 445 & \\
\hline & $B C D$ & & & D & & $P<0.05$ \\
\hline Total Respondents & 463 & 22 & 34 & 189 & 708 & \\
\hline
\end{tabular}

\begin{tabular}{|l|l|c|c|}
\hline \multicolumn{4}{|l|}{ Table 7: Poisoning of stored medications. } \\
\hline No & Medication & Frequency & Percentages \\
\hline 1 & Paracetamol & 6 & $18.18 \%$ \\
\hline 2 & Ibuprofen & 3 & $9.09 \%$ \\
\hline 3 & Multivitamin & 3 & $9.09 \%$ \\
\hline 4 & Pseudoephedrine & 2 & $6.06 \%$ \\
\hline 5 & Ranitidine & 2 & $6.06 \%$ \\
\hline 6 & B-Sitosterol & 2 & $6.06 \%$ \\
\hline 7 & Isotretinoin & 1 & $3.03 \%$ \\
\hline 8 & Lovastatin & 1 & $3.03 \%$ \\
\hline 9 & Triprolidine & 1 & $3.03 \%$ \\
\hline 10 & Aspirin & 1 & $3.03 \%$ \\
\hline 11 & Hyoscine & 1 & $3.03 \%$ \\
\hline 12 & Chlorpheniramine & 1 & $3.03 \%$ \\
\hline 13 & Benzopyrazine & 1 & $3.03 \%$ \\
\hline 14 & Esomeprazole & 1 & $3.03 \%$ \\
\hline 15 & Omega 3 & 1 & $3.03 \%$ \\
\hline 16 & Betaserc & 1 & $3.03 \%$ \\
\hline 17 & Diclofenac & 1 & $3.03 \%$ \\
\hline 18 & Loratadine & 1 & $3.03 \%$ \\
\hline 19 & Amoxicillin & 1 & $3.03 \%$ \\
\hline 20 & Mometasone Furoate & 1 & $3.03 \%$ \\
\hline 21 & Tacrolomus & 1 & $3.03 \%$ \\
\hline & & & \\
\hline
\end{tabular}

considering medications as dangerous substance that children can be exposed to. Females tended to store medications away from chemical substances more than males as they are the most responsible members taking care of children and family. However, if the quantity of stored medications was greater, then the responders' cared less with regard to the storage of medicines away from the chemical substance. It should be noted that irrespective of the quantity of medication, it is dangerous to store them next to chemicals, but the responders payed more attention to the increased number of the stored medications rather than the place of storage. In this study, the responders did not store multiple medications in the same container, regardless of their age or educational status. This shows that they had a good knowledge on how to avoid poisoning due to chemical interaction between the substance of the stored medications. The number of poisoning cases did not vary with gender or educational status. This shows that during studies, there were no awareness sessions and no educational campaigns and no general awareness lectures conducted by responsible healthcare institutions at any time. In addition, the knowledge regarding storage place or method of disposing the medications were the same between both genders or between educational levels. Since we found that all participants stored the medications in bathroom where they can be easily exposed to children. In addition, disposal of medications in the trash was found to be more accessible to children of any age irrespective of gender. Frattaroli et al. obtained similar results in Qatar households. ${ }^{[4,6]}$ Most of the responders stored medication in their refrigerator in our study. All these factors contributed to the increased risks of children toward medication poisoning by several folds. Therefore, a large-scale study is needed to understand the implications of child poisoning and their relations with stored medicines in Saudi Arabia. Disposal of unused medication is as important as storing them. In this study, we found that in outpatient pharmacy setting, more number of subjects tended to dispose medicines in the garbage than what has been reported 
in a previous study. ${ }^{[4]}$ Only a few percentage (22 (3.1\%)) of subjects returned unused medications to the pharmacy, which was found to be less than what has reported in a previous study. ${ }^{[2]}$ This data is alarming as these improperly disposed medications will add to the poisoning levels of underground water and other resources. In addition, this data clarifies that the need to focus on educating most responder's with young age groups (18-29 years) and driving awareness to make a positive change regarding this issue. University students must also be made to focus on such awareness campaigns. Further studies are needed to know the effects of improperly disposed medicines. As these studies will also help in raising the awareness regarding storage of medication at home, disposal and other related issues. Moreover, considering the easy accessibility, efforts should be made to make storage of medicine to be childproof.

\section{CONCLUSION}

The results of this study point toward the improper methods of storing medications which results in accidental poisoning in Al-Qassim region. Awareness campaigns and more educational sessions should be conducted through social media can be utilized to educate the public regarding the proper methods of storing medications, as well as the need to return the unused medications to the pharmacies if they do not know or have no knowledge on how to dispose the medications in an appropriate method. Pharmacists should collaborate with other healthcare providers in preventing poisoning and conducting the awareness programs stressing on the need for safe storage and identification of the right ways to dispose of unused medications.

\section{ACKNOWLEDGEMENT}

None.

\section{CONFLICT OF INTEREST}

None.

\section{ABBREVIATIONS}

SPSS: Statistical Packages for Social Sciences; WHO: World health Organization.

\section{REFERENCES}

1. Gracia-Vásquez SL, Ramírez-Lara E, Camacho-Mora IA, CantúCárdenas LG, Gracia-Vásquez YA, Esquivel-Ferriño PC, et al. An analysis of unused and expired medications in Mexican households. Int J Clin Pharm. 2014.

2. Alazmi A, Alhamdan H, Abualezz R, Bahadig F, Abonofal N, Osman M. Patients' Knowledge and Attitude toward the Disposal of Medications. J Pharm. 2017;1-9.

3. Law AV, Sakharkar P, Zargarzadeh A, Tai BWB, Hess K, Hata M, et al. Taking stock of medication wastage: Unused medications in US households. Res Soc Adm Pharm. 2015

4. Kheir N, El Hajj MS, Wilbur K, Kaissi RML, Yousif A. An exploratory study on medications in Qatar homes. Drug Healthc Patient Saf. 2011;3(1):99-106.

5. Sawalha AF, Sweileh WM, Tufaha MT, Al-Jabi DY. Analysis of the pattern of acute poisoning in patients admitted to a governmental hospital in palestine. Basic Clin Pharmacol Toxicol. 2010.

6. Frattaroli S, Shields W, Omaki E, Molloy M, Gielen AC. How Are Prescription Medications Stored in Urban Homes Where Children Live? Opportunities for Poisoning Prevention. Clin Pediatr (Phila). 2017.

7. Consumer Product Safety Commission. CPSC NEISS On-Line Query System. CPSC.gov [Internet]. [cited 2018 Nov 18]. Available from: https:// www.cpsc.gov/cgibin/NEISSQuery/home.aspx

8. Franklin RL, Rodgers GB. Unintentional Child Poisonings Treated in United States Hospital Emergency Departments: National Estimates of Incident Cases, Population-Based Poisoning Rates and Product Involvement. Pediatrics. 2008. 